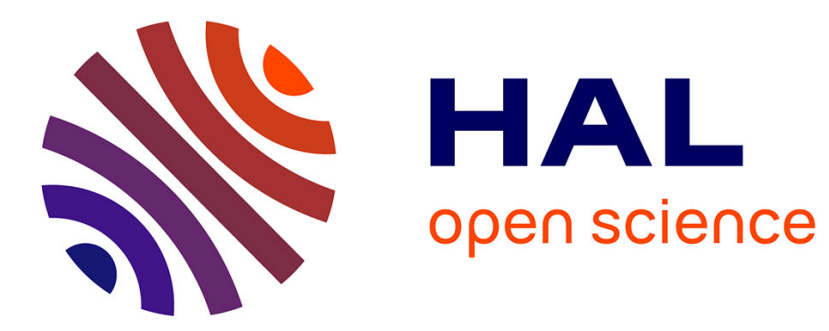

\title{
Dynamic lot sizing with product returns and remanufacturing
}

\author{
Ruud Teunter, Pelin Bayindir, Wilco van den Heuvel
}

\section{To cite this version:}

Ruud Teunter, Pelin Bayindir, Wilco van den Heuvel. Dynamic lot sizing with product returns and remanufacturing. International Journal of Production Research, 2006, 44 (20), pp.4377-4400. 10.1080/00207540600693564 . hal-00512905

\section{HAL Id: hal-00512905 \\ https://hal.science/hal-00512905}

Submitted on 1 Sep 2010

HAL is a multi-disciplinary open access archive for the deposit and dissemination of scientific research documents, whether they are published or not. The documents may come from teaching and research institutions in France or abroad, or from public or private research centers.
L'archive ouverte pluridisciplinaire HAL, est destinée au dépôt et à la diffusion de documents scientifiques de niveau recherche, publiés ou non, émanant des établissements d'enseignement et de recherche français ou étrangers, des laboratoires publics ou privés. 




\section{Dynamic lot sizing with product returns and remanufacturing}

\begin{tabular}{|r|l|}
\hline Journal: & International Journal of Production Research \\
\hline Manuscript ID: & TPRS-2005-IJPR-0384.R1 \\
\hline Manuscript Type: & Original Manuscript \\
\hline Complete List of Authors: & $\begin{array}{l}\text { Teunter, Ruud; Lancaster University Management School, } \\
\text { Department of Management Science } \\
\text { Bayindir, Pelin; Middle East Technical University, Industrial } \\
\text { Engineering } \\
\text { van den Heuvel, Wilco; Erasmus University Rotterdam, Econometric } \\
\text { Institute }\end{array}$ \\
\hline Keywords: & BATCH SIZING \\
\hline Keywords (user): & reverse logistics, remanufacturing \\
\hline & \\
\hline $\begin{array}{l}\text { Note: The following files were submitted by the author for peer review, but cannot be converted } \\
\text { to PDF. You must view these files (e.g. movies) online. }\end{array}$ \\
\hline $\begin{array}{l}\text { TPRS-2005-IJPR-0384.R1.tex } \\
\text { TPRS-2005-IJPR-0384.R1.bib }\end{array}$ \\
\hline
\end{tabular}

\section{$\checkmark$ ScholaroNE" \\ Manuscript Central}




\title{
Dynamic lot sizing with product returns and remanufacturing
}

\author{
Ruud H. Teunter* \\ Department of Management Science, Lancaster University Management School, \\ Lancaster, LA1 4YX, UK, \\ tel/fax(ext.): +44 (1524) 594326/844885, e-mail: r.teunter@lancaster.ac.uk \\ Z. Pelin Bayındır \\ Dept. of Industrial Engineering, Middle East Technical University, \\ TR-06531 Ankara/Turkey, \\ tel(ext.): +90 (312) 210 4793, e-mail: bayindir@ie.metu.edu.tr \\ Wilco van den Heuvel \\ Econometric Institute and Erasmus Research Institute of Management, \\ Erasmus University Rotterdam, \\ PO Box 1738, Burg. Oudlaan 50, 3000 DR Rotterdam, The Netherlands, \\ tel/fax(ext.): +31 (10) 4081321/9162, e-mail: wvandenheuvel@few.eur.nl
}

March 2, 2006

\begin{abstract}
We address the dynamic lot sizing problem for systems with product returns. The demand and return amounts are deterministic over the finite planning horizon. Demands can be satisfied by manufactured new items, but also by remanufactured returned items. The objective is to determine those lot sizes for manufacturing and remanufacturing that minimize the total cost composed of holding cost for returns and (re)manufactured products and set-up costs. Two different set-up cost schemes are considered; there is either a joint set-up cost for manufacturing and remanufacturing (single production line) or separate set-up costs
\end{abstract}

\footnotetext{
${ }^{*}$ corresponding author
} 
(dedicated production lines). For the joint set-up cost case, we present an exact, polynomial time dynamic programming algorithm. For both cases, we suggest modifications of the well-known Silver Meal (SM), Least Unit Cost (LUC) and Part Period Balancing (PPB) heuristics. An extensive numerical study reveals a number of insights. The key ones are that under both set-up cost schemes: (1) the SM and LUC heuristics perform much better than PPB, (2) increased variation in the demand amounts can lead to reduced cost, showing that predictability is more important than variation, and (3) periods with more returns than demand should, if possible, be avoided by 'matching' demand and return.

Keywords: inventory management, lot sizing, reverse logistics, remanufacturing

\section{Introduction}

Dynamic lot sizing, i.e., planning manufacturing/production orders over a number of future periods in which demand is dynamic and deterministic, is one of the most extensively researched topics in production and inventory control. See Silver et al. [21] for a general overview, and Brahimi et al. [3] for a recent and extensive review of single item models. However, the literature on dynamic lot sizing with returns, where remanufacturing of those returns is an alternative for manufacturing, is very scarce.

Remanufacturing can be defined as the recovery of returned products, often involving disassembly, cleaning, testing, part replacement/repair, and reassembly operations, after which they are as-good-as-new. The latter term distinguishes remanufacturing from other recovery types such as material and energy recycling. See Thierry et al. [26] for a comparison of recovery types.

Environmental legislation, societal pressure, and economic opportunities have motivated many firms to get involved with product remanufacturing, especially over the past 10 years. Products that are nowadays remanufactured include single use camera's, machine tools, medical instruments, copiers, automobile engines, computers, aviation equipment, telephone equipment, and tires (see Ferrer [7], [8], Kandebo [14], Lund [18], Sivinski and Meegan [22], Sprow [23], Thierry et al. [26], and Toktay et al. [27]).

The scientific literature on remanufacturing and product recovery in general has also been 
growing at an increasing rate over the past two decades. Overviews are provided by Fleischmann et al. [9], Guide et al. [12], and Gupta and Gungor [13]. For a discussion of more recent results we refer readers to Dekker et al. [5].

A lot of attention has centered on operations management decisions for systems where manufactured and remanufactured products are not distinguished, i.e., are identical. These systems especially pose new challenges for production and inventory control, since manufacturing and remanufacturing are two alternative sources leading to the same serviceable products, and hence they need to be controlled simultaneously. Note that though remanufactured products are by definition as-good-as-new, i.e. of the same quality as manufactured products, they are not always considered to be identical. Some counter examples are retreated tires (Ferrer [7]) and reconditioned copiers (Ayres et al. [1]) that are sold at a lower price than newly manufactured products, although manufacturers give the same quality warranties. Examples where no distinction between remanufactured and manufactured products is made, include single use camera's (Toktay et al. [27]), pallets and containers (Golany et al. [11], Kelle and Silver [15]), and service parts for cars (Driesch et al. [6] and Van der Laan [16]) and computers (Fleischmann et al. [10]).

In this paper, we focus on systems where manufactured and remanufactured products are identical, and refer to them as serviceable products or serviceables for short. We will study the dynamic lot sizing problem for such systems. Quite a few papers have recently been written on production and inventory control for these systems (see also the before mentioned overviews), but just a few of them deal with dynamic lot sizing. Most authors instead study systems with stationary demand and return, and analyze policies that use fixed order/production quantities. Those that include stochasticity of demand and return, usually further characterize the policy by order(-up-to) levels, and apply the following two-step approach for finding a near-optimal policy. First, determine a near optimal order quantity by balancing fixed ordering and holding costs. Second, determine order(-up-to) levels or equivalently safety stock levels by balancing holding and shortage costs. This decomposition approach is traditionally also used for systems without remanufacturing (Chan et al. [4]). Dynamic lot sizing is an alternative to the first step for situations with non-stationary demand. 
Using dynamic lot sizing is quite common in production environments without remanufacturing, as it is imbedded in the MRP methodology. They can be solved exactly using the famous Wagner-Whitin algorithm or approximately using heuristics such as Silver-Meal, Least Unit Cost or Part Period Balancing, nowadays available in most ERP/APO packages. See e.g. Silver et al. [21] for descriptions of the algorithm and heuristics. In this paper, we generalize the Wagner-Whitin algorithm (under a set-up cost assumption) and test modifications of the before mentioned heuristics for systems with manufacturing and remanufacturing. The few papers that have been written on dynamic lot sizing with remanufacturing so far, did not consider heuristics. Furthermore, they either provided a much more complex algorithm or made more restrictive system assumptions. An overview of the previous contributions and a more detailed account of the differences with our system are given in Section 2 .

After providing the literature overview, the remainder of this paper is organized as follows. In Section 3, the model is presented. Two cases are considered with either a joint set-up cost or separate set-up costs for manufacturing and remanufacturing. The case with a joint set-up cost is treated in Section 4. The exact algorithm is presented, and the heuristics are described. In an extensive numerical experiment, sensitivity analyses are performed on the effect of system parameters on the heuristic performances and on the minimum cost for the optimal solution. Section 5 deals with separate set-up costs. Heuristics are described and tested. Again, sensitivity analyses are performed in a numerical experiment. We end with conclusions and offer directions for future research in Section 6.

\section{Literature review on dynamic lot sizing with remanufacturing}

Richter and Sombrutzki [19] and Richter and Weber [20] study special cases of the problem. In their first model, it is assumed that the number of returns is sufficient for satisfying all demands without delay, and therefore manufacturing is not considered. The second model does consider the manufacturing option. However, results are only derived for the special case that the number of returns in the first period is at least as large as the total demand over the planning horizon. 
So in fact, the manufacturing option is not needed in the second model either, but may be used for economic reasons if holding returns is very costly.

Golany et al. [11] study the problem without restrictive assumptions on the number of returns and they also assume that there is a disposal option. They show that the lot sizing problem with remanufacturing can be formulated as a network flow problem. Using this formulation, they prove that the problem is NP-hard for general concave costs. For the special case with linear costs and hence zero set-up costs, they provide a polynomial-time algorithm.

Beltran and Krass [2] study the lot sizing problem with returns that can be directly reused, i.e., for which no remanufacturing is needed. They show that it suffices to consider solutions that satisfy the "zero-inventory property", and use this property to develop a dynamic programming (DP) algorithm with cubic time-complexity that determines the optimal manufacturing and disposal decisions for the case of concave cost functions. If procurement cost and disposal cost are non-decreasing over time, then the problem can be solved in quadratic time.

In this paper we study the lot sizing problem with remanufacturing of returns, without restrictions on the number of returns and with set-up costs included. Two different set-up cost schemes are considered. In the first model variant, there is a joint set-up cost for manufacturing and remanufacturing, which is suitable if manufacturing and remanufacturing operations are performed on the same production line using the same production resources. In the second model variant, there are separate set-up costs for manufacturing and remanufacturing, in line with situations where there are separate production lines. Note that all four above discussed papers assumed separate cost functions for manufacturing and remanufacturing, but none proposed algorithms for the general case with no return restrictions and with set-up costs included. Moreover, none tested heuristics.

\title{
3 Model
}

Table 1 lists the notations that will be used.

\author{
** PLACE TABLE 1 HERE **
}


We address dynamic lot sizing problems for systems with product returns. Demand and remanufacturable return amounts are known for all periods of the planning horizon. We remark that in practice, forecasts will only be available. Therefore, as is described in Section 1, safety stocks or safety lead times should be 'added' before implementing a solution from the dynamic lot sizing problem. The determination of those safety stocks/times is beyond the scope of this paper. Note also that remanufacturable return amounts are known. The actual (forecasted) return amounts may be larger, but in many situations not all returns will be of sufficient quality to be remanufactured and yield loss needs to be incorporated. For ease of notation, we will refer to remanufacturable returned products simply as returned products or returns in what follows.

It is important to remark that the setting that we have in mind is not one where the lot sizing problem is over at the end of the finite planning horizon and any remaining stock of returns needs to be disposed of. It is the difficulty of generating demand forecasts, especially for the distant future, which drives the use of a finite planning horizon. This is the common reason for using a finite planning horizon when solving dynamic lot sizing problems in production environments without remanufacturing.

Demands can be satisfied by manufactured/procured new products and by remanufactured returned products. In Figure 1, a simple sketch of the system is depicted.

\section{** PLACE FIGURE 1 HERE **}

Note that there is no disposal option for remanufacturable returned products. Recent research on infinite horizon models by Fleischmann et al. [10], Van der Laan and Salomon [17], and Teunter and Vlachos [25] has shown that such an option will not lead to a considerable cost reduction, unless the remanufacturable return rate as a percentage of the demand rate is unrealistically high (above 90\%) and the demand rate is very small (less than 10 per year). Although our model assumes a finite horizon, this is done because of forecasting issues and not because the lot sizing problem ends, as mentioned before. In this setting, returns remaining unused at the end of the planning horizon do not have to be disposed of. We remark that this setting is not appropriate, and our model without a disposal option not suitable, if unused returns do need to be disposed of at the end of the finite planning horizon, as may be the case in seasonal 
retailing.

The objective is to determine the production plan, i.e., the number of products manufactured and remanufactured at each period, such that the total cost over the planning horizon is minimized. The following cost items are included:

- fixed set-up cost of manufacturing and remanufacturing,

- inventory holding cost for returns and serviceables.

We assume that in any period the sequence of events is as follows. First, returns come in and then manufacturing and remanufacturing take place. Next, demand occurs and finally holding costs are incurred for the serviceables and returns in stock at the end of the period.

The set-up costs are modelled in two different ways: either there is a joint set-up cost for manufacturing and remanufacturing, or there are separate costs. The first approach is suitable if manufacturing and remanufacturing operations are performed on the same production line using the same production resources, whereas the second is suitable for situations with dedicated production lines. We remark that in practice, there could also be mixed settings, e.g. a single production line with (partially) dedicated resources. Those situations could be modelled by having both a joint (major) set-up cost for starting production as well as separate (minor) setup costs for manufacturing and remanufacturing. That more general modelling of set-up costs will not be considered here, but the heuristics that we will test can easily be adjusted for such a situation.

It is assumed that the holding cost rate for serviceables is at least that for holding returns. Since remanufacturing adds value to a product, this is a practical assumption. For a detailed discussion on how to set holding cost rates in a system with remanufacturing of product returns, we refer interested readers to Teunter et al. [24].

Note that variable cost of manufacturing and remanufacturing are not included in the model. Recall that although our model uses a finite horizon, we assume that this is done because of the inability to forecast demand in the distant future, and not because (re)manufacturing ends and any remaining stock of unused returns needs to be disposed of. Indeed, since we exclude the disposal option, all returns arriving to the system are eventually remanufactured. In the 
long term, lot sizing decisions therefore do not affect the total variable manufacturing and remanufacturing costs incurred (if these costs are time stationary). So, lot sizing decisions only effect set-up and holding costs and should find the right balance between them. The following simple example illustrates that the inclusion of variable costs can distort this balance.

Consider an 8 week problem with 10 demands and 9 returns in each week. The variable manufacturing and remanufacturing costs are 500 and 250, respectively. The holding costs per period per item for returns and serviceables are 0.5 and 1 , respectively. Note that this ratio of holding cost to variable cost is realistic, as it reflects an annual holding cost rate of around $10 \%(0.10 / 52 \times 500 \approx 1)$. There is a joint set-up cost of 20 per order.

If variable costs are included, then the optimal solution is to manufacture 1 and remanufacture 9 items in each period. The corresponding total set-up and holding costs are 160 and 0 , respectively. The optimality of this solution with remanufacturing in each period is easily checked. Any solution without remanufacturing in each period is not able to remanufacture all returns and hence increases the variable cost by at least 250 , whereas the maximum savings in set-up cost are 160 .

If variable costs are not included, then the optimal solution is to manufacture 11 and remanufacture 9 items in week 1 , and to manufacture 2 and remanufacture 18 items in weeks 3,5 and 7 . The corresponding total set-up and holding costs are 80 and 58 , respectively. This solution, compared to the optimal solution with variable costs included, reduces the summed set-up and holding costs from 160 to 148 by balancing the two cost components.

We assume that the manufacturing and remanufacturing lead times are zero. For the model with separate set-up costs, the non-zero lead times can be handled in the following way. If the actual remanufacturing lead time is more than one period, say $L_{r}$ periods, then the problem 
can easily be adapted to a corresponding one with a zero remanufacturing lead time by shifting returns $L_{r}$ periods forward. Each remanufacturing order in a solution for the zero lead time problem then has to be shifted $L_{r}$ periods backwards for the actual problem. If the actual manufacturing lead time is more than one period, say $L_{m}$ periods, then the problem requires no modification and the solution can, similarly to remanufacturing, be adapted by shifting each manufacturing orders in a solution for the zero lead time problem $L_{m}$ periods backwards for the actual problem.

For the model with a joint set-up cost, the above transformation to a corresponding zero lead time problem can only be done if the lead times for manufacturing and manufacturing are equal. If lead times differ, then shifting manufacturing and remanufacturing orders by different numbers of periods could alter the total set-up costs incurred. The assumption of equal lead times seems reasonable if manufacturing and remanufacturing operations are performed on the same production line, but may not be justified in all situations.

Without loss of generality, we can also assume that the initial stocks of serviceables and returns are both zero and that there is a positive demand in the first period. To see this, consider the general problem with possibly non-zero stocks $I_{0}^{r}$ of returns and $I_{0}^{s}$ of serviceables at the end of period 0 . It is obvious that the first set-up should be placed in the first period $f$ for which cumulative demand $\sum_{i=1}^{f} D_{i}$ is larger than $I_{0}^{s}$. The relevant lot sizing problem is therefore from that period $f$ with positive demand onwards, and starts with $I_{0}^{s}-\sum_{i=1}^{f-1} D_{i}<D_{f}$ serviceables and $I_{0}^{r}+\sum_{i=1}^{f-1} R_{i}$ returns in stock at the end of period $f-1$. This problem can easily be transformed to an equivalent problem with zero initial (at the end of period $f-1$ ) stocks by subtracting $I_{0}^{s}-\sum_{i=1}^{f-1} D_{i}$ from the demand in period $f$ and adding $I_{0}^{r}+\sum_{i=1}^{f-1} R_{i}$ to the return in period $f$. Therefore, any general lot sizing problem with non-zero initial stocks can be transformed to an equivalent problem with zero initial stocks and positive demand in the first period. 


\section{Joint set-up cost for manufacturing and remanufacturing}

The lot sizing problem under the joint manufacturing and remanufacturing set-up cost can be modelled as a mixed integer linear programming problem (MILP) as follows:

$$
\begin{aligned}
& \min \sum_{t=1}^{T}\left\{K \delta_{t}+h^{r} I_{t}^{r}+h^{s} I_{t}^{s}\right\} \\
& \text { subject to } \\
& I_{t-1}^{r}+R_{t}-x_{t}^{r}=I_{t}^{r} \text { for } t=1, \ldots, T \\
& I_{t-1}^{s}+x_{t}^{r}+x_{t}^{m}-D_{t}=I_{t}^{s} \text { for } t=1, \ldots, T \\
& x_{t}^{r}+x_{t}^{m} \leq M_{t} \delta_{t} \text { for } t=1, \ldots, T \\
& \delta_{t} \in\{0,1\}, x_{t}^{r}, x_{t}^{m}, I_{t}^{r}, I_{t}^{s} \geq 0 \text { and } M_{t}=\sum_{i=t}^{T} D_{i} \text { for } t=1, \ldots, T .
\end{aligned}
$$

Constraints (1) and (2) assure the inventory balance in return and serviceable stocks, respectively. Constraint (3) keep track of the set-ups; whenever a manufacturing or a remanufacturing lot is produced, a set-up is made and the production (the sum of the amount manufactured and remanufactured) in period $t$ will never exceed the total demand in periods $t, \ldots, T$.

Next, we will derive some optimality conditions that will provide the basis for an exact dynamic programming algorithm and a number of heuristics. The conditions are presented in the form of two lemmas. The first lemma states that for any optimal solution, the stock at the beginning of any period with a set-up is zero. This lemma is a generalization of the well-known zero-inventory property for the original lot sizing problem without returns.

Lemma 1 Any optimal solution satisfies the zero-serviceable-inventory-property: for any period with a set-up it holds that the stock of serviceables at the beginning of the period is zero, i.e., $I_{t-1}^{s} \delta_{t}=0$ for $t=1,2, \ldots, T$.

Proof See the appendix. 
We remark that Lemma 1 can also be used to solve the MILP more efficiently by adding the constraints $I_{t-1}^{s} \leq\left(1-\delta_{t}\right) \sum_{i=t}^{T} D_{i}$ for $t=1,2, \ldots, T$.

The second lemma shows that priority is given to remanufacturing option, i.e. that any optimal solution only manufactures in a certain period if the initial stock of returns at the beginning of that period is insufficient for remanufacturing the entire lot.

Lemma 2 Any optimal solution satisfies the following property: in every period where products are manufactured, the stock of returns at the end of that period is zero, i.e., $I_{t}^{r} x_{t}^{m}=0$ for $t=1,2, \ldots, T$.

Proof See the appendix.

\subsection{Exact dynamic programming algorithm}

The dynamic programming algorithm that is proposed in this section is a generalized version of the one proposed by Wagner and Whitin [30] for solving the dynamic lot sizing problem without returns. See Table 1 for notations. Note that, for ease of presentation, some of the notations are also used for period 0 .

The algorithm starts by considering period 0 only. Clearly, the stock of returns at the end of that period is 0 . So, $S_{0}=\{0\}, f_{0}(0)=0$, and $f_{0}=0$. The algorithm then recursively solves the lot sizing problem until period $k=1,2, \ldots, T$ by deriving $S_{l, k}$ (for all $\left.l=1, \ldots, k\right), S_{k}, f_{l, k}(n)$ (for all $l=1, \ldots, k$ and $n \in S_{l, k}$ ), $f_{k}(n)$ (for all $n \in S_{k}$ ), and $f_{k}$. The recursive equations are derived below.

Consider the problem until period $k$. If the last set-up is in period $l, l \leq k$, then all the returns in periods $l+1$ until $k$, i.e. $\sum_{i=l+1}^{k} R_{i}$, will be in stock at the end of period $k$. Moreover, if there are returns left in stock at the end of period $l$, then those products will also be in stock at the end of period $k$. From Lemma 2 it follows that there can only be returns left in stock at the end of period $l$ if the stock at the end of period $l-1$ plus the returns in period $l$ is larger than the size of the order in period $l$. Using Lemma 1 it follows that the size of the order in 
period $l$ is $\sum_{i=l}^{k} D_{i}$. We therefore get

$$
S_{l, k}=\bigcup_{j \in S_{l-1}}\left\{\left(j+R_{l}-\sum_{i=l}^{k} D_{i}\right)^{+}+\sum_{i=l+1}^{k} R_{i}\right\}
$$

Clearly, we further have

$$
S_{k}=\bigcup_{l=1}^{k} S_{l, k}
$$

Next, we derive the recursive expression for $f_{l, k}(n)$. As explained above, if the last set-up is in period $l$, then the stock of returns at the end of period $k$ is equal to $\sum_{i=l+1}^{k} R_{i}$ plus any stock that may be left at the end of period $l$. Two cases are distinguished.

- There is no stock left at the end of period l. Since remanufacturing is preferred to manufacturing (Lemma 2), this case occurs if the stock at the end of period $l-1$ plus the returns $R_{l}$ in period $l$ is at most the order size $\sum_{i=l}^{k} D_{i}$ in period $l$. The associated holding cost for returns in periods $l, \ldots, k$ is $h^{r} \sum_{i=l+1}^{k}(k+1-i) R_{i}$, since the returns in period $i, i=l+1, \ldots, k$, incur a holding cost at the end of periods $i, \ldots, k$. The associated holding cost for serviceables in periods $l, \ldots, k$ is $h^{s} \sum_{i=l+1}^{k}(i-l) D_{i}$, since the products that satisfy the demands in period $i, i=l+1, \ldots, k$, incur a holding cost at the end of periods $l, l+1, \ldots, k-1$.

- Some stock is left at the end of period $l$. Then the stock at the end of period $k$ is more than $\sum_{i=l+1}^{k} R_{i}$. To attain stock level $n$ at the end of period $k$, there should be $n-\sum_{i=l+1}^{k} R_{i}$ left at the end of period $l$ and hence (since Lemma 2 implies that there is no manufacturing) $n-\sum_{i=l+1}^{k} R_{i}-R_{l}+\sum_{i=l}^{k} D_{i}=n+\sum_{i=l}^{k}\left(D_{i}-R_{i}\right)$ left at the end of period $l-1$. The associated holding cost for returns in periods $l, \ldots, k$ is therefore $h^{r}\left(\left(n-\sum_{i=l+1}^{k} R_{i}\right)(k-l+1)+\sum_{i=l+1}^{k}(k+1-i) R_{i}\right)=h^{r}\left(n(k-l+1)-\sum_{i=l+1}^{k}(i-l) R_{i}\right)$. The associated holding cost for serviceables in periods $l, \ldots, k$ is the same as for the first case. 
So, we get

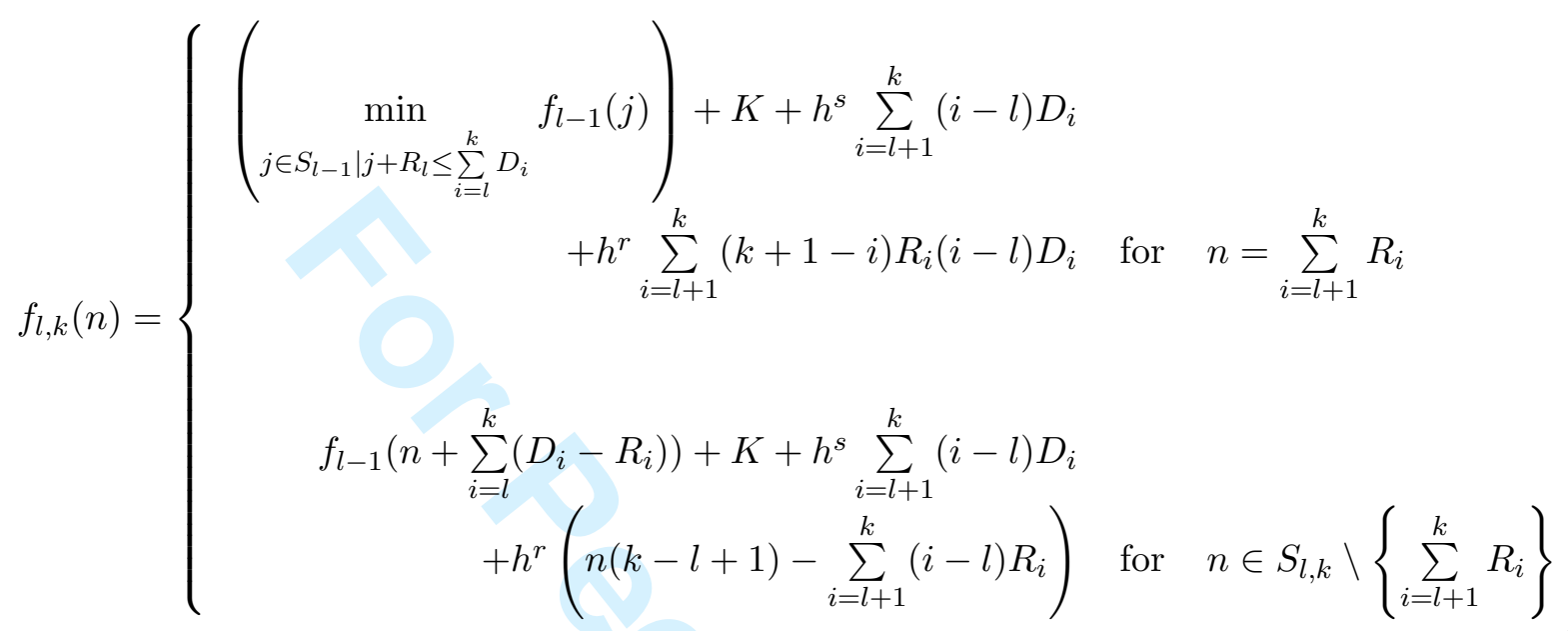

Clearly, we further have

$$
f_{k}(n)=\min _{l \in\{1, \ldots, k\} \mid n \in S_{l, k}} f_{l, k}(n) \text { for } n \in S_{k}
$$

and

$$
f_{k}=\min _{n \in S_{k}} f_{k}(n) \text { for } k=1, \ldots, T
$$

Using the above results, we formulate the algorithm in the frame below. Step 1 initializes the values for period 0 and then sets the current period $k$ to 1 . In the recursive Step 2 , the optimal lot sizes until period $k$ are determined. When $k=T$ is reached, the algorithm goes to the final Step 3, where the optimal lot sizes are determined 'backwards'. This backward determination of the optimal lot sizes is similar to that for the original lot sizing problem without product returns. We do not describe it mathematically, since that is straightforward and would require additional notations. 


\section{Dynamic Programming algorithm for joint set-up cost}

Step 1: $S_{0}:=\{0\}, f_{0}(0)=0, f_{0}=f_{0}(0)=0 . k:=1$.

Step 2: $\quad$ For all $l=1, \ldots, k$, determine $S_{l, k}$ using (5). Determine $S_{k}$ using (6). For all $l=1, \ldots, k$ and all $n \in S_{l, k}$, determine $f_{l, k}(n)$ using $(7)$. For all $n \in S_{k}$, determine $f_{k}(n)$ using (8). Determine $f_{k}$ using (9).

Step 3: If $k=T$ then go to Step 4 . else $\quad k:=k+1$, and go to Step 2 .

Step 4: The minimal cost until period $t, t=1, \ldots, T$ is $f_{T}$. The corresponding lot sizes can be determined backwards.

The algorithm runs in polynomial time, as is stated in the theorem below.

Theorem 1 The DP algorithm runs in $O\left(T^{4}\right)$ time.

Proof The proof is based on the fact that $S_{k}$, the number of different return stock levels at the end of period $k$, is quadratically bounded by $k$. For details we refer to the appendix.

For the numerical examples that we will consider in Section 4.3 with $T=12$ periods, the algorithm takes only a fraction of a second. Based on a recent paper by Van den Heuvel and Wagelmans [29], we suspect that the run time of the algorithm will be just a few seconds even for large, from a practical point of view, problem instances with up to 40 periods. In that paper, it is shown that it takes less than 3 seconds in the worst case to solve 2000-period instances of a capacitated lot sizing problem by an $\mathrm{O}\left(T^{2}\right)$ DP algorithm. So a rough estimation is that instances of approximately $\sqrt{2000} \approx 45$ periods can be solved within a few seconds by our $\mathrm{O}\left(T^{4}\right)$ algorithm.

Although our algorithm can determine an optimal solution efficiently, heuristics may be still be preferred in practice because they are faster, easier to code and implement, and easier for the 
user to understand. With respect to speed, one should keep in mind that lot sizing problems are typically solved for tens of thousands of items. However, it is only fair to add that based on our numerical experiments, the lot sizing problem for a 12 period horizon could be solved for ten thousand items in about 15 minutes (although that requires state-of-the-art Cplex software). As for ease of coding and implementation, the exact Dynamic Programming formulation is much more tedious to code than the heuristics that we will propose. Coding the exact MIP formulation would be less tedious, but would require knowledge of integer programming and availability of the appropriate software. The heuristics that we will propose are also much easier to understand, for the mathematically inexperienced user, than the exact formulations. As for the current practice in solving lot sizing problems (without returns), we have never encountered a case where exact MIP or Wagner-Whitin algorithms are applied. Indeed, even ERP packages such as SAP do not include these exact algorithms, but offer simple heuristics only.

\subsection{Heuristics}

The most well-known heuristics for original lot sizing problems without returns are Silver Meal (SM), Least Unit Cost (LUC), and Part Period Balancing (PPB). See e.g. Silver et al. [21] for detailed descriptions. All three heuristics are myopic in the sense that they focus solely on the next order and ignore costs associated with future orders. Moreover, they only consider solutions that satisfy the zero-inventory property. The SM heuristic chooses the order that minimizes the cost per period. The LUC heuristic chooses the order that minimizes the cost per ordered unit. The PPB heuristic chooses the lot size that minimizes the difference between the set-up cost and the total holding cost. We propose modified versions of these three heuristics.

Since the zero-inventory property still holds for situations with returns (see Lemma 1) the restriction to solutions that satisfy this property remains justified. Further, based on Lemma 2, it is logical to restrict to remanufacture-first solutions. The only modification for the original heuristics that is required concerns the calculation of the total cost associated with an order. The modified cost expression is derived below.

Let $C_{l, k}(m)$ denote the total cost in interval $[l, k]$ if the stock of returns (determined by the 
previous lot sizing decisions) at the end of period $l-1$ is $m$, and an order is placed in period $l$ that is sufficient until period $k$, that is of size $\sum_{i=l}^{k} D_{i}$. Clearly, there are returns left in stock at the end of period $l$ if and only if the stock $m$ at the end of period $l-1$ plus the returns $R_{l}$ in period $l$ is larger than the order size $\sum_{i=l}^{k} D_{i}$. If products are left in stock at the end of period $l$, then they will remain in stock until the end of period $k$. So, the associated return holding cost is $h^{r}(k-l+1)\left(m+R_{l}-\sum_{i=l}^{k} D_{i}\right)^{+}$. Expressions for the return holding costs associated with returns after period $l$ and for serviceable holding costs can easily be derived using arguments similar to those that lead to (7). This gives

$$
C_{l, k}(m)=K+h^{r}\left((k-l+1)\left(m+R_{l}-\sum_{i=l}^{k} D_{i}\right)^{+}+\sum_{i=l+1}^{k}(k+1-i) R_{i}\right)+h^{s} \sum_{i=l+1}^{k}(i-l) D_{i} .
$$

All three heuristics use this modified cost expression, and are otherwise unchanged from the original version.

We remark that running times are not an issue when applying the heuristics. One can show that the running times of the heuristics are linear in the planning horizon $T$. For example, the term $\sum_{i=l}^{k} D_{i}$ in (10) can be calculated as follows. In the initialization phase of the heuristic, compute the values $D(1, t)=\sum_{i=1}^{t} D_{i}$ which can be done in linear time. Then, whenever needed, the value of $\sum_{i=l}^{k} D_{i}$ can simply be calculated by $D(1, k)-D(1, l-1)$ which can be done in constant time. Similar 'tricks' can be used to calculate the values of the other summations in $(10)$.

\subsection{Numerical experiment}

Four different types of demand and return patterns are considered: stationary, linearly increasing, linearly decreasing, and seasonal. The return ratio, i.e. the mean return rate as a percentage of the mean demand rate, is set to either $30 \%, 50 \%$, or $70 \%$. The total number of demand and return patterns considered are 10 and 22, respectively. For each pattern, four series of realizations are generated, so that the total number of demand and return series are 40 and 88 , respectively. 
The serviceable holding cost per period is normalized at 1 . The remanufacturing holding cost is relatively small (0.2), moderate $(0.5)$, or large (0.8). For the joint/separate set-up costs, 3 values are considered. We remark that based on some preliminary investigations, these cost values are chosen such that during the planning horizon, which is fixed at 12 periods, the number of periods with a set-up for the optimal solution varies between 2 and 6 .

For details on the demand and return patterns, and on the cost parameter values, we refer to Table 2 .

\section{PLACE TABLE 2 HERE **}

A full factorial design is applied, so that the total number of examples is $40 \times 88 \times 3 \times 3=$ 31,680. For each example, we determine the optimal solution as well as the three heuristic solutions. We measure the performance of a heuristic by the percentage increase in the total cost compared to an optimal solution, which we refer to as the "error".

A first important result is that the average error over all examples for PPB $(24.8 \%)$ is much larger than that for SM (3.0\%) and LUC (4.2\%). Apparently, balancing ordering and holding costs does not lead to a near-optimal solution. Indeed, further analysis of all optimal solutions revealed that, on average, the division of total cost into holding and set-up is not 50-50 but roughly 40-60. The poor performance of PPB can be further explained by the combined effect of fluctuations in returns and demands. Silver et al. [21] report that for traditional systems without returns, the performance of PPB is negatively affected by increased fluctuations.

Next, we perform a sensitivity analysis to determine the effects of the demand pattern, return pattern, return rate, and cost parameters on the performance of the heuristics. The results are summarized in Table 3. This table reports the average error, the standard deviation of the errors, and the maximum error. The minimum error is always $0 \%$ and therefore omitted. Our discussion of the results will therefore concentrate on the SM and LUC heuristics, because of their overall superior performance compared to PPB.

\section{** PLACE TABLE 3 HERE **}

It appears that under most demand and cost settings, SM performs slightly better then LUC 
both in terms of average error and maximum error. Moreover, the average performances of both SM and LUC are quite robust. Except for the scenario with a large set-up cost $(K=2000)$, the average errors for SM and LUC are less then $5 \%$ and $7 \%$, respectively. On the downside, the poor worst case performance is robust as well. Both SM and LUC have a maximum error of more than $15 \%$ under most demand/return scenarios and cost settings. In the remainder of this section, we will discuss some of the sensitivity with respect to demand and cost settings in terms of average error.

SM performs significantly better than LUC for seasonal demand, especially if fluctuations are large. Increased demand fluctuations generally (though not for all patterns) deteriorate the performances of SM and LUC. An increase in the return rate also affects the performances negatively. Overall, however, the effect of the demand and return setting is small.

Cost values have more effect on the performances, with similar effects for SM and LUC. An increase in the unit holding cost of returns affects the performances negatively, showing that the suboptimality is mainly due to the scheduling of remanufacturing orders. The set-up cost has the largest effect on performance. As expected, the larger the set-up cost, the poorer the performance. However, it is important to realize that the poorer performance for larger set-up costs is (mainly) caused by the larger order sizes and hence smaller numbers of orders. Due to the myopic shortsighted nature of the heuristics, the last order in a heuristic solution is often much too small. For $K=2000$ there are typically just 2 orders over the planning horizon, compared to 6 on average for $K=200$, and therefore the relative effect on the cost of a too small last order is larger. In other words, the poorer performance for larger set-up costs is due to the relatively smaller planning horizon (in terms of number of orders placed) and does not result from unsuitability of the proposed heuristics for large $K$.

\section{Separate set-up costs for manufacturing and remanufacturing}

The MILP formulation is similar to that for the joint set-up cost case except for the separation of the set-up cost. 


$$
\begin{aligned}
\min \sum_{t=1}^{T}\left\{K^{r} \delta_{t}^{r}+K^{m} \delta_{t}^{m}+h^{r} I_{t}^{r}+h^{s} I_{t}^{s}\right\} & \\
\text { subject to } & \\
I_{t-1}^{r}+R_{t}-x_{t}^{r} & =I_{t}^{r} \text { for } t=1, \ldots, T \\
I_{t-1}^{r}+x_{t}^{r}+x_{t}^{m}-D_{t} & =I_{t}^{s} \text { for } t=1, \ldots, T \\
x_{t}^{r} & \leq M_{t} \delta_{t}^{r} \text { for } t=1, \ldots, T \\
x_{t}^{m} & \leq M_{t} \delta_{t}^{m} \text { for } t=1, \ldots, T \\
\delta_{t}^{r}, \delta_{t}^{m} \in\{0,1\}, x_{t}^{r}, x_{t}^{m}, I_{t}^{r}, I_{t}^{s} & \geq 0 \text { and } M_{t}=\sum_{i=t}^{T} D_{i} \text { for } t=1, \ldots, T
\end{aligned}
$$

Recall from Section 4 that for the case with a joint set-up cost, optimal solutions satisfy the zero-inventory and remanufacture-first properties. These properties enabled us to construct an exact algorithm of polynomial time-complexity. The following simple example shows that the properties no longer hold when there are separate set-up costs. Let $K^{r}=10, K^{m}=10$, $h^{r}=1, h^{s}=2, T=2, D_{1}=2, D_{2}=100, R_{1}=1$, and $R_{2}=98$. It is easy to check that the optimal solution is to manufacture 3 products in period 1 and remanufacture 99 in period 2, with corresponding total cost 23. This solution satisfies neither of the two properties. Therefore, we are not able to develop a polynomial DP algorithm for the case with separate set-up costs.

In fact, we conjecture that the problem with separate set-up costs is NP-hard. Besides the fact that the zero-inventory property and the remanufacture-first property no longer hold, there is another result that strongly points in this direction. Van den Heuvel [28] considers the same problem as in this section, except that variable (re)manufacturing costs are included and costs may vary over time. He shows that this problem is NP-hard under the following conditions: costs are constant over time, manufacturing and remanufacturing set-up costs are equal $\left(K^{m}=K^{r}\right)$, holding cost for returns is smaller than holding cost for serviceables $\left(h^{r}<h^{s}\right.$, which will typically hold if remanufacturing is motivated economically), and remanufacturing cost is zero. So the only difference with our model is the inclusion of constant manufacturing cost. It can easily be 
shown for the joint set-up cost problem with inclusion of variable costs under these conditions, that the two properties still hold, the DP algorithm can still be applied, and therefore the problem remains polynomially solvable. So, apparently, it is not the inclusion of variable costs but the separation of set-up costs which is responsible for the NP-hardness. Therefore, as our problem is slightly different from the problem in Van den Heuvel [28], we conjecture that our problem is NP-hard.

We will propose and test a number of heuristics. As for the joint set-up cost problem, these heuristics are generalized versions of the well-known Silver-Meal, Least Unit Cost, and Part Period Balancing heuristics for systems without remanufacturing. All three heuristics simultaneously determine the manufacturing and the remanufacturing order sizes. We also tested heuristics that determine the order sizes sequentially, first for remanufacturing and then for manufacturing based on the remaining 'net demand'. However, it turned out that their performances were very poor compared to those of the simultaneous heuristics. Therefore, the sequential heuristics will not be presented.

\section{$5.1 \quad$ Heuristics}

The generalized versions of the well-known Silver-Meal, Least Unit Cost, and Part Period Balancing heuristics only consider solutions that satisfy the zero-inventory property for serviceables. Although, as discussed above, Lemma 1 does not hold in general for the separate set-up cost problem, we expect that for most realistic cases, a near-optimal solution that satisfies the zeroinventory property exists. The extensive numerical study in Section 5.2 will confirm that the cost increase of the best zero-inventory solution compared to the optimal solution is generally less than $2 \%$.

The heuristics do consider solutions that may not always remanufacture first. This is essential, since there can be situations with large set-up costs and few returns available, where it is clearly better to keep the returns in stock for now and manufacture only, rather than to remanufacture as well as manufacture. Therefore, besides remanufacture-first orders, the heuristics consider manufacture-only orders. Next, we will derive cost expressions for both types of orders. 
The expression for the cost associated with a remanufacture-first order is similar to that for the case with joint set-up costs. Expression (10) only needs to be modified by including the set-up costs if a (re)manufacturing order is placed. Let $I$ (condition) denote the indicator function, which is one if the condition is satisfied and zero otherwise. Using similar arguments as those leading to (10), we get the following expression for the cost $C R_{l, k}(m)$ in interval $[l, k]$ if the returns stock at the end of period $l-1$ is $m$ and a remanufacture-first order is placed in $l$ that is sufficient until $k$.

$$
\begin{aligned}
C R_{l, k}(m)= & I\left(m+R_{l}>0\right) K^{r}+I\left(m+R_{l}<\sum_{i=l}^{k} D_{i}\right) K^{m}+h^{s} \sum_{i=l+1}^{k}(i-l) D_{i} \\
& +h^{r}\left((k-l+1)\left(m+R_{l}-\sum_{i=l}^{k} D_{i}\right)^{+}+\sum_{i=l+1}^{k}(k+1-i) R_{i}\right)
\end{aligned}
$$

If a manufacturing-only order is placed in period $l$ for interval $[l, k]$ and the returns stock at the end of period $l-1$ is $m$, then the returns stock at the end of period $i, i=l, \ldots, k$, is $m+\sum_{s=l}^{t} R_{s}$. The corresponding cost is therefore

$$
C M_{l, k}(m)=K^{m}+h^{s} \sum_{i=l+1}^{k}(s-l) D_{i}+h^{r}\left((k-l+1) m+\sum_{i=l+1}^{k}(k+1-i) R_{i}\right)
$$

Aside from the consideration of two order types and the corresponding modified cost expressions, the heuristics are identical to the original ones for systems with manufacturing only.

\subsection{Numerical experiment}

The same demand patterns, return patterns, and cost parameter values are considered as in the previous experiment, but of course the set-up costs for manufacturing and remanufacturing can now have different values. See Table 2. The total number of examples is 95,040.

We start by justifying the focus on heuristics that only consider solutions satisfying the zero-inventory property. The best zero-inventory solution is determined by solving the MILP model in Cplex with the following additional restrictions: $I_{t-1}^{s} \leq\left(1-\delta_{t}^{m}\right) D(t, T)$ and $I_{t-1}^{s} \leq$ $\left(1-\delta_{t}^{r}\right) D(t, T)$. These force the inventory at the end of period $t-1$ to be zero when a 
(re)manufacturing order is place in period $t$, thereby enforcing a solution to satisfy the ZIproperty.

For $38.1 \%$ of the examples, there is in fact an optimal solution that satisfies this property. For a further $14.4 \%$ of the examples, the cost increase of the heuristics compared to the optimal solution is less than one per cent. The average cost increase over all examples is less than two per cent.

The remainder of this section deals with heuristical performances. As for the case with a joint set-up cost, it turns out that the PPB performs much worse than SM and LUC for all demand/return patterns and cost values. Furthermore, SM again performs slightly better than LUC under most scenarios. The average error over all examples is $8.3 \%$ for SM, $9.0 \%$ for LUC, and $19.8 \%$ for PPB.

Table 4 gives the results of a sensitivity analysis with respect to demand/return patterns and costs.

\section{** PLACE TABLE 4 HERE **}

Most results are similar to those for the joint set-up cost case. The effects of a change in set-up costs are more complex, as there are two types of set-up costs now. Recall that for the joint set-up cost case, it was observed that an increase in the set-up cost leads to a poorer performance of all heuristics. This was explained by reduced number of orders and hence the (relatively) stronger effect of a too small last order. For the separate set-up cost case, we see the same effect from an increase in the manufacturing set-up cost. However, an increase in the remanufacturing set-up cost has the opposite effect; the performances of all heuristics improve. A look at the optimal solutions provided the following explanation. In cases where remanufacturing set-up is more costly than a manufacturing set-up, the optimal solution often place no remanufacturing batches at all, and neither do the heuristic solutions. As is known from the literature, the heuristics perform well in pure manufacturing situations. 


\section{Conclusion}

We studied the dynamic lot sizing problem for systems where manufactured new products and remanufactured returned products are used to satisfy the same demands. The set-up cost was modelled in two different ways. Relevant for situations with a single or with dedicated production lines, either a joint set-up cost or separate set-up costs are incurred for placing (re)manufacturing orders.

For both models, the problem was formulated as a mixed integer program (MIP). The problem with a joint set-up cost turned out to be least complex. Based on the so-called zero-inventory and remanufacture-first properties, a polynomial DP algorithm was provided. For situations with separate set-up costs, these properties no longer hold and the problem is conjectured to be NP-hard.

In practice, heuristic procedures will often be preferred to the exact MIP formulations and even to the DP algorithm. We therefore presented and tested modified versions of the wellknown Silver-Meal (SM), Least Unit Cost (LUC), and Part Period Balancing (PPB) heuristics, both under a joint set-up cost and under separate set-up costs.

In extensive numerical experiments, we calculated the optimal solution for a large number of examples under both models, and performed a sensitivity study on the effect of model parameters on the optimal solution using global regression on its cost. The main conclusions were the same for both models. First, a counterintuitive result was that an increase in demand variability often leads to a decrease in cost. This is explained by the increased opportunity to place orders in periods with high demand and stock for periods with low demand. It shows that improving the predictability of demand is more important than reducing its variation, at least with respect to lot sizing costs. A second result with a similar explanation was that a positive trend in the demand leads to higher cost. A third result was that a large negative trend in return usually increases the cost, as the initial surplus of returns leads to additional stocking costs. This shows that returns should be matched with demands as much as possible.

In the same experiments, the heuristic solutions were determined and their performance was measured by the cost error, i.e., the increase in cost compared to the optimal solution. For 
both cost models, it turned out that SM performs slightly better than LUC and a lot better than PPB. A sensitivity study further revealed that this result is quite robust with respect to demand/return patterns and cost settings. The average performance of SM was good (average cost error of $3.0 \%)$ for the joint set-up cost model and fair (8.4\%) for the separate set-up cost model. For both models, the performance of all heuristics deteriorated with an increasing holding cost for returns, showing that the suboptimality is mainly due to the scheduling of remanufacturing orders.

Even though some improvement in performance can be expected if the heuristics are applied in a rolling horizon setting, which they are likely to be in practise, our performance results for modifications of well-known heuristics suggest that there is room for improvement, especially for the separate set-up cost model. One direction for further research is therefore to propose and test alternative heuristics. Other interesting research avenues are to prove the conjecture that the problem is NP-hard for separate set-up costs, to test the heuristics in a rolling horizon setting, derive 'horizon results' similar to standard dynamic lot sizing, and to modify and test heuristics for 'mixed' cases with a joint set-up cost as well as separate set-up costs, or with an even more general set-up cost function.

\section{A Proofs}

Proof of Lemma 1 Consider any solution $\pi$. Since the initial stock (at the end of period 0) of serviceables is zero, the property obviously holds for the first period (in which there is a set-up since demand is positive). Now consider any other period $t \geq 2$ with a set-up under solution $\pi$, and let $s$ denote the preceding period with a set-up. So, $s$ and $t$ are successive set-up periods under solution $\pi$. We shall complete the proof by showing that if the stock of serviceables is positive at the beginning of period $t$, then an alternative feasible solution $\pi^{\prime}$ with lower cost can be constructed. We consider two cases.

- $\pi$ only remanufactures in period $s$ :

Then $\pi^{\prime}$ remanufactures one less product in $s$ and one more in $t$, i.e., $x_{s}^{\prime r}=x_{s}^{r}-1$ and $x_{t}^{\prime r}=x_{t}^{r}+1$. Clearly, this solution is feasible because $x_{s}^{r}>0$ and it has the same number 
Proof of Lemma 2 Consider any solution $\pi$ that does not satisfy the property. Then there must be some period $t, 1 \leq t \leq T$, with manufacturing and with a positive stock of returns at the end, i.e., $I_{t}^{r} x_{t}^{m}>0$. Let $v$ be the remanufacturing period proceeding $t$. We consider two cases.

- period $v$ does not exist:

Consider an alternative solution $\pi^{\prime}$ which manufactures one less product and remanufactures one more product in period $t$, i.e., $x_{t}^{\prime m}=x_{t}^{m}-1$ and $x_{t}^{\prime r}=x_{t}^{r}+1$. Clearly, solution $\pi^{\prime}$ is feasible as $x_{t}^{m}>0$ and $I_{t}^{r}>0$. But then we have $I_{i}^{\prime r}=I_{i}^{r}-1$ and $I_{i}^{\prime s}=I_{i}^{s}$ for $i=t, \ldots, T$ and hence we have a reduction in holding cost for returns of $h^{r}(T-t+1)>0$.

- period $v$ exists:

An alternative solution $\pi^{\prime}$ is to manufacture one less product and remanufacture one more product in period $t$, and to manufacture one more product and remanufacture one less product during in period $v$, i.e., $x_{t}^{\prime m}=x_{t}^{m}-1, x_{t}^{\prime r}=x_{t}^{r}+1, x_{v}^{\prime m}=x_{v}^{m}+1$ and $x_{v}^{\prime r}=x_{v}^{r}-1$. Again, solution $\pi^{\prime}$ is feasible as $x_{t}^{m}>0$ and $x_{v}^{r}>0$ and we have $I_{i}^{\prime r}=I_{i}^{r}-1$ and $I_{i}^{\prime s}=I_{i}^{s}$ for $i=t, \ldots, v-1$. Because the set-up costs and holding costs for serviceables remain the same, we have a reduction in holding cost for returns of $h^{r}(v-t)>0$.

Therefore, in both cases $\pi$ cannot be optimal. 
Before giving the proof of Theorem 1, we start by stating two lemmas on the cardinality of sets $S_{k}$ and $S_{l, k}$.

Lemma 3 For $1 \leq k \leq T$ we have that $\left|S_{k}\right|=O\left(k^{2}\right)$.

Proof Consider some solution up to period $k$ satisfying Lemmas 1 and 2. By definition, the set $S_{k}$ contains all possible ending inventories of returns $I_{k}^{r}$ at the end of period $k$, possibly including zero. Now assume that we have some positive ending inventory, i.e., $I_{k}^{r}>0$. Furthermore, let $q$, $1 \leq q \leq k$, be the last period before $k$ satisfying $I_{q-1}^{r}=0$. So, $I_{t}^{r}>0$ for all $t=q, \ldots, k$. Such a period exists because $I_{0}^{r}=0$. We consider the following two cases.

- There is no production in periods $q, \ldots, k$. This implies that all returns in those periods accumulate, so that

$$
I_{k}^{r}=\sum_{t=q}^{k} R_{t} .
$$

Note that there is positive demand and therefore production in period 1. Hence, $q \in$ $\{2, \ldots, k\}$ and this case gives $k-1$ possible values of $I_{k}^{r}$.

- Let $p, q \leq p \leq k$, be the first period after $q$ with non-zero production. Because $I_{t}^{r}>0$ for $t=q, \ldots, k$, there is no manufacturing in periods $p, \ldots, k$. Otherwise Lemma 2 would be violated. This implies that all demands in periods $p, \ldots, k$ must be satisfied by the returns in periods $q, \ldots, k$ (if possible), so that

$$
I_{k}^{r}=\sum_{t=q}^{k} R_{t}-\sum_{t=p}^{k} D_{t} .
$$

Note that $q=1$ implies that $p=1$. Furthermore, because $q \leq p \leq k$ for $q \geq 2$, this case gives $\frac{1}{2} k(k-1)+1$ possible values of $I_{k}^{r}$.

So in total, we have $1+(k-1)+\left(\frac{1}{2} k(k-1)+1\right)=\frac{1}{2} k(k+1)+1=O\left(k^{2}\right)$ possible values of $I_{k}^{r}$, which implies that $\left|S_{k}\right|=O\left(k^{2}\right)$. This completes the proof of Lemma 3 .

Lemma 4 For $1 \leq k \leq T$ we have that $\left|S_{l, k}\right|=O\left((l-1)^{2}\right)$. 
Proof This follows directly from (5) and Lemma 3.

Proof of Theorem 1 Using lemmas 3 and 4, we will show that the time it takes to calculate all values of $(7),(8)$, and (9) is at most $O\left(T^{4}\right)$ for each of the equations.

- Equation (7): Consider any fixed periods $k$ and $l$ with $1 \leq l \leq k \leq T$. It takes $O\left((l-1)^{2}\right)$ time to compute $f_{l, k}(n)$ for $n=\sum_{i=l+1}^{k} R_{i}$ because $\left|S_{l-1}\right|=O\left((l-1)^{2}\right)$ (see Lemma 4). Furthermore, for a fixed $n \in S_{l, k} \backslash\left\{\sum_{i=l+1}^{k} R_{i}\right\}$ it takes constant time to calculate $f_{l, k}(n)$. So $f_{l, k}(n)$ can be computed in $O\left((l-1)^{2}\right)$ time for all $n \in S_{l, k} \backslash\left\{\sum_{i=l+1}^{k} R_{i}\right\}$, and hence $f_{l, k}(n)$ can be calculated in $O\left((l-1)^{2}\right)$ for all $n \in S_{l, k}$. Because there are $O\left(T^{2}\right)$ combinations of $k$ and $l$, the computation of $f_{l, k}(n)$ takes $O\left(T^{4}\right)$ time in total.

- Equation (8): For any fixed period $k(1 \leq k \leq T)$ and fixed $n \in S_{l, k}$, the computation of $f_{k}(n)$ takes $O(k)$ time. Because $\left|S_{k}\right|=O\left(k^{2}\right)$ (see Lemma 3) and $1 \leq k \leq T$, the computation of $f_{k}(n)$ can be performed in $O\left(T^{4}\right)$ time in total.

- Equation (9): Because $\left|S_{k}\right|=O\left(k^{2}\right)$ (see Lemma 3), it follows immediately that $f_{k}$ can be calculated in $O\left(k^{2}\right)$ time for any fixed period $k(1 \leq k \leq T)$. So it takes $O\left(T^{3}\right)$ time to compute all values of $f_{k}$.

Therefore, the algorithm runs in $O\left(T^{4}\right)+O\left(T^{4}\right)+O\left(T^{3}\right)=O\left(T^{4}\right)$ time.

\section{References}

[1] R. Ayres, G. Ferrer, and T. van Leynseele. Eco-efficiency, asset recovery and remanufacturing. European Management Journal, 15(5):557-574, 21997.

[2] J.L. Beltran and D. Krass. Dynamic lots sizing with returning items and disposals. IIE Transactions, 34:437-448, 2002.

[3] N. Brahimi, S. Dauzere-Peres, N.M. Najid, and A. Nordli. Single item lot sizing problems. European Journal of Operational Research, 168:1-16, 2006. 
[4] L.M. A. Chan, A. Muriel, Z.-J. Shen, and D. Simchi-Levi. On the effectiveness of zeroinventory-ordering policies for the economic lot-sizing model with a class of piecewise linear cost structures. Operations Research, 50(6):1058-1067, 2002.

[5] R. Dekker, M. Fleischmann, K. Inderfurth, and L.N. van Wassenhove. Reverse Logistics: Quantitative Models for Closed-Loop Supply Chains. Springer-Verlag, Berlin Heidelberg, 2004 .

[6] H. Driesch, H.E. Van Oyen, and S.M. Flapper. Recovery of car engines: the mercedes-benz case. In S.D.P. Flapper and J.A.E.E. van Nunen, editors, Multistage Inventory Models and Techniques. Springer Verlag, Berlin, Germany, 2005.

[7] G. Ferrer. The economics of personal computer remanufacturing. Resources, Conservation and Recycling, 21:79-108, 1997.

[8] G. Ferrer. The economics of tire remanufacturing. Resources, Conservation and Recycling, 19:221-255, 1997.

[9] M. Fleischmann, J.M. Bloemhof-Ruwaard, R. Dekker, E. van der Laan J.A.E.E. van Nunen, and L.N. van Wassenhove. Quantitative models for reverse logistics: a review. European Journal of Operational Research, 103:1-17, 1997.

[10] M. Fleischmann, J.A.E.E. van Nunen, and Gräven. Integrating closed-loop supply chains and spare-parts management at ibm. Interfaces, 33(6):44-56, 2003.

[11] B. Golany, J. Yang, and G. Yu. Economic lot-sizing with remanufacturing options. IIE Transactions, 33:995-1003, 2001.

[12] V.D.R. Guide, V. Jayaraman, R. Srivastava, and W.C. Benton. Supply-chain management for recoverable manufacturing systems. Interfaces, 30(3):125-142, 2000.

[13] S.M. Gupta and A. Gungor. Issues in environmentally conscious manufacturing and product recovery. Computers and Industrial Engineering, 36(4):811-853, 1999. 
[14] S.W. Kandebo. Grumman, U.S. navy under way in f-14 remanufacturing program. Aviation Week and Space Technology, December 17th:44-45, 1990.

[15] P. Kelle and E.A. Silver. Purchasing policy of new containers considering the random returns of previously issued containers. IIE Transactions, 21(4):349-354, 1989.

[16] E. van der Laan. The effects of remanufacturing on inventory control. PhD thesis, Erasmus University Rotterdam, the Netherlands, 1997.

[17] E. van der Laan and M. Salomon. Production planning and inventory control with remanufacturing and disposal. European Journal of Operational Research, 102(2):264-278, 1997.

[18] R. Lund. Remanufacturing. Technology Review, 87(2):18-23, 1984.

[19] K. Richter and M. Sombrutzki. Remanufacturing planning for the reverse wagner/whitin models. European Journal of Operational Research, 121:304-315, 2000.

[20] K. Richter and J. Weber. The reverse wagner/whitin model with variable manufacturing and remanufacturing cost. International Journal of Production Economics, 71:447-456, 2001 .

[21] E.A. Silver, D.F. Pyke, and R. Peterson. Inventory Management and Production Planning and Scheduling. John Wiley and Sons, New York, 1998.

[22] J.A. Sivinski and S. Meegan. Case study: Abbott labs formalized approach to remanufacturing. In APICS Remanufacturing Seminar Proceedings, pages 27-30, 1993.

[23] E. Sprow. The mechanics of remanufacture. Manufacturing Engineering, pages 38-45, 1992.

[24] R.H. Teunter, E. van der Laan, and K. Inderfurth. How to set the holding cost rates in average cost inventory models with reverse logistics? OMEGA The International Journal of Management Science, 28:409-415, 2000. 
[25] R.H. Teunter and D. Vlachos. On the necessity of a disposal option for returned products that can be remanufactured. International Journal of Production Economics, 75:257-266, 2002 .

[26] M. Thierry, M. Salomon, J.A.E.E. van Nunen, and L.N. van Wassenhove. Strategic issues in product recovery management. California Management Review, 37(2):114-135, 1995.

[27] B. Toktay, L.M. Wein, and Zenios S.A. Inventory management of remanufacturable products. Management Science, 46(11):1412-1426, 2000.

[28] W. van den Heuvel. Econometric institute report. Technical Report EI 2004-46, Econometric Institute, Erasmus University Rotterdam, The Netherlands, 2004.

[29] W. van den Heuvel and A.P.M. Wagelmans. An efficient dynamic programming algorithm for a special case of the capacitated lot-sizing problem. Computers $\&$ Operations Research, page forthcoming, 2005.

[30] H.M. Wagner and T.M. Whitin. Dynamic version of the economic lot size model. Management Science, 5:89-96, 1958.

\section{Acknowledgements:}

We thank the anonymous referees and the editors for their helpful comments on the original version of this paper. 


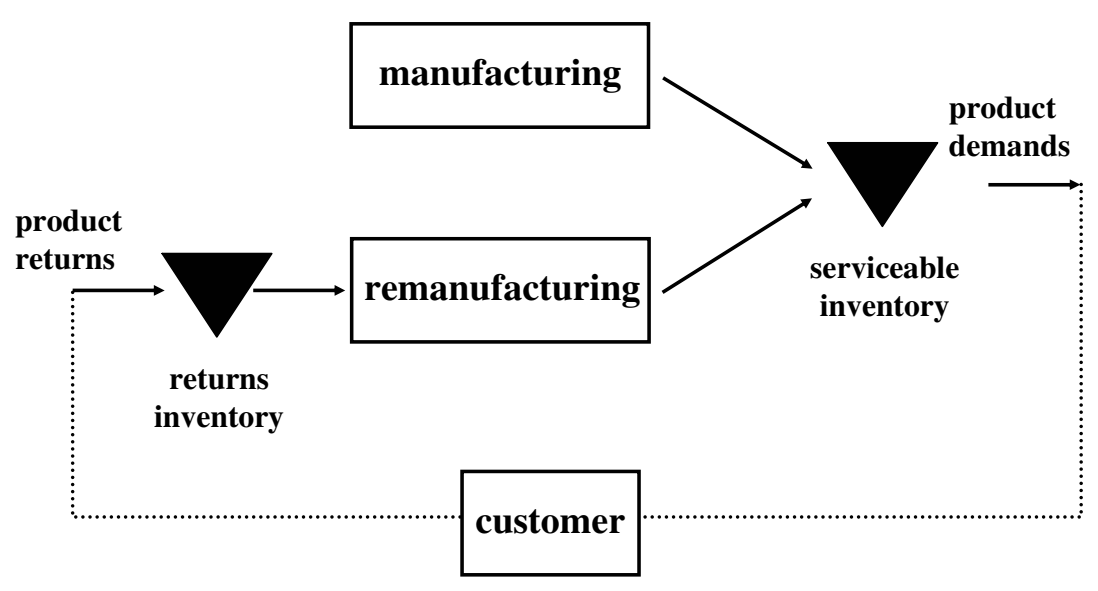

Figure 1: Inventory system with remanufacturing. 


\section{General}

Planning horizon

$t \quad$ Index for periods in the planning horizon, $t=1, \ldots, T$

$R_{t} \quad$ Number of returns received at the beginning of period $t$

$D_{t} \quad$ Number of products demanded in period $t$

$K \quad$ (joint) set-up cost

$K^{r} \quad$ (separate) Set-up cost for remanufacturing

$K^{m} \quad$ (separate) Set-up cost for manufacturing

$h^{r} \quad$ Unit holding cost for returns per period

$h^{s} \quad$ Unit holding cost of end-products (serviceables) per period

Mixed integer linear programming (MILP) formulation

$x_{t}^{r} \quad$ Number of products remanufactured in period $t$

$x_{t}^{m} \quad$ Number of products manufactured in period $t$

$I_{t}^{r} \quad$ Inventory level of returns at the end of period $t$

$I_{t}^{s} \quad$ Inventory level of serviceables at the end of period $t$

$\delta_{t} \quad$ (joint) 0-1 indicator variable for remanufacturing set-up in period $t$

$\delta_{t}^{r} \quad$ (separate) $0-1$ indicator variable for remanufacturing set-up in period $t$

$\delta_{t}^{m} \quad$ (separate) 0 -1 indicator variable for manufacturing set-up in period $t$

$M \quad$ Large integer

Dynamic programming (DP) algorithm

$f_{k} \quad$ Minimum cost in periods $1, \ldots, k$ (if periods $k+1, \ldots, T$ are ignored)

$f_{k}(n) \quad$ Minimum cost in periods $1, \ldots, k$ (if periods $k+1, \ldots, T$ are ignored) with $n$ returns in stock at the end of period $k$

$f_{l, k}(n) \quad$ Minimum cost in periods $1, \ldots, k$ if the last order is placed in periods $l$ with $n$ returns in stock at the end of period $k$

$S_{k} \quad$ Set of possible returns stock levels at the end of period $k$

$S_{l, k} \quad$ Set of possible returns stock levels at the end of period $k$ if the last order is placed in periods $l$

(joint) Cost in interval $[l, k]$ if the returns stock at the end of period $l-1$ is $m$ and an order is placed in period $l$ that is sufficient until period $k$

$C R_{l, k}(m) \quad$ (separate) Cost in interval $[l, k]$ if the returns stock at the end of period $l-1$ is $m$ and a remanufacture-first order is placed in $l$ that is sufficient until $k$

$C M_{l, k}(m) \quad$ (separate) Cost in interval $[l, k]$ if the returns stock at the end of period $l-1$ is $m$ and a manufacture only order is placed in $l$ that is sufficient until $k$

$I$ (condition) Indicator function, which is one if the condition is satisfied and zero otherwise

Table 1: Notations. 


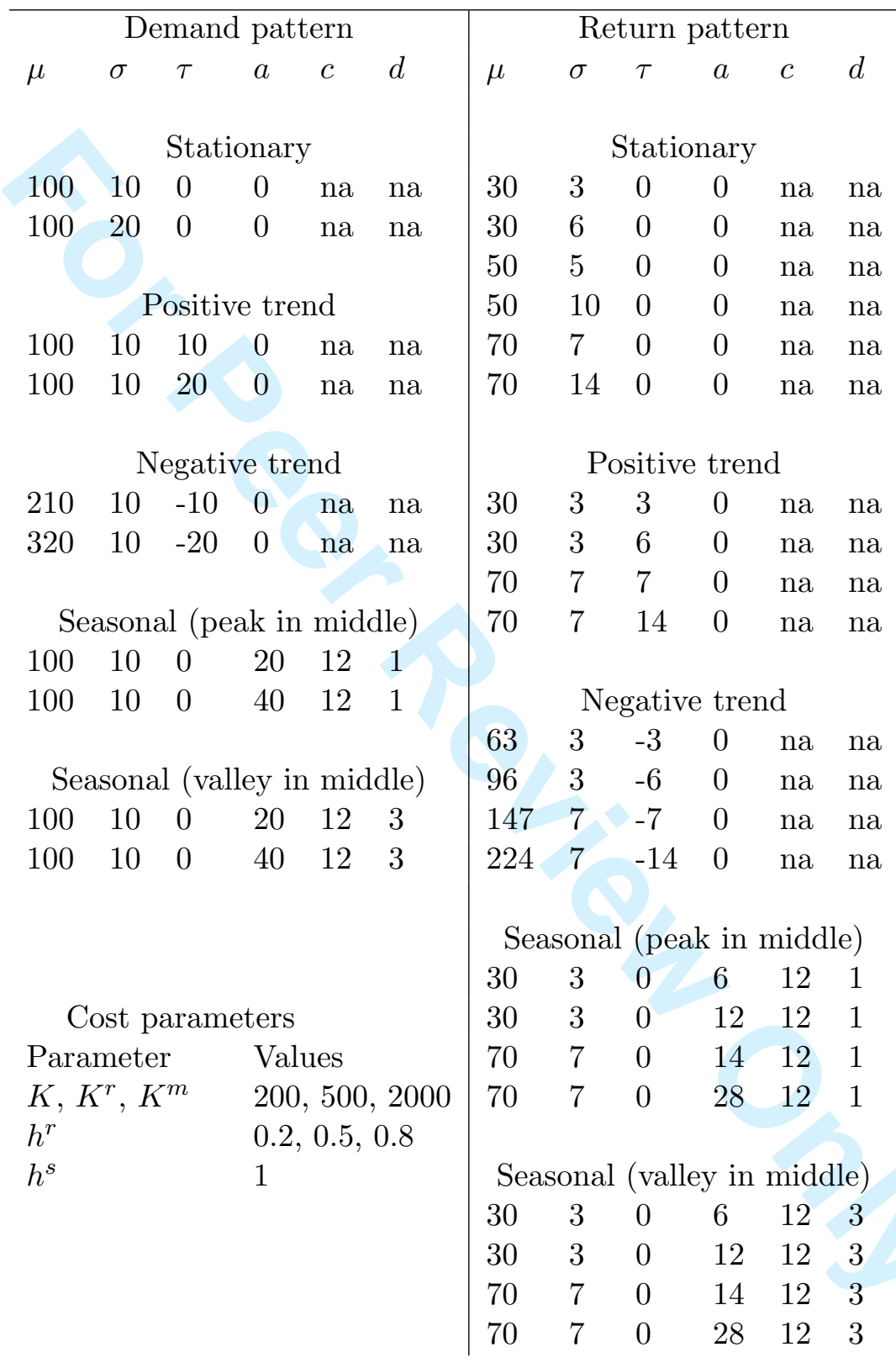

Table 2: Experimental Setting. The demand and return patterns are generated according to $D_{t}=\mu+\tau(t-1)+a \sin \left(\frac{2 \pi t}{c}+d \frac{\pi}{2}\right)+\varepsilon_{t}$ for $t=1, \ldots, T$, where $\mu$ is the starting level of the pattern, $\tau$ is the trend level, $a$ is the amplitude of the cycle, $c$ is the cycle length, $d$ determines the peak of the cycle and $\varepsilon_{t}(t=1, \ldots, T)$ are independently normally distributed random variables with standard deviation $\sigma$. 


\begin{tabular}{|c|c|c|c|c|c|c|c|c|c|}
\hline & \multicolumn{9}{|c|}{ Percentage Cost Error } \\
\hline & \multicolumn{3}{|c|}{ Average } & \multicolumn{3}{|c|}{ Standard deviation } & \multicolumn{3}{|c|}{ Maximum } \\
\hline & SM & LUC & PPB & SM & LUC & PPB & SM & LUC & PPB \\
\hline All instances & 3.0 & 4.2 & 24.8 & 4.9 & 6.5 & 34.9 & 25.1 & 37.0 & 222.3 \\
\hline Demand pattern & & & & & & & & & \\
\hline Stationary & 3.3 & 3.5 & 32.5 & 5.7 & 5.7 & 42.8 & 23.3 & 25.4 & 211.7 \\
\hline -Small variance & 2.8 & 2.4 & 31.9 & 5.2 & 4.9 & 42.8 & 20.3 & 22.8 & 207.4 \\
\hline -Large variance & 3.8 & 4.6 & 33.0 & 6.1 & 6.1 & 42.9 & 23.3 & 25.4 & 211.7 \\
\hline Positive trend & 2.0 & 2.4 & 10.2 & 3.2 & 3.7 & 15.2 & 22.6 & 22.6 & 121.9 \\
\hline -Small trend & 1.3 & 3.4 & 12.2 & 2.3 & 4.7 & 19.0 & 22.6 & 22.6 & 121.9 \\
\hline -Large trend & 2.7 & 1.4 & 8.1 & 3.8 & 1.7 & 9.8 & 11.1 & 17.7 & 73.3 \\
\hline Negative trend & 3.2 & 3.0 & 15.9 & 3.8 & 4.0 & 21.1 & 18.3 & 18.3 & 121.4 \\
\hline -Small trend & 3.6 & 2.5 & 15.8 & 4.2 & 2.3 & 28.9 & 18.3 & 15.3 & 121.4 \\
\hline -Large trend & 2.8 & 3.5 & 15.9 & 3.3 & 5.1 & 17.5 & 16.5 & 18.3 & 110.4 \\
\hline Seasonal & 3.3 & 6.1 & 32.7 & 5.6 & 8.3 & 39.5 & 25.1 & 37.0 & 222.3 \\
\hline -Small amplitude & 3.3 & 4.6 & 30.5 & 5.9 & 7.2 & 47.8 & 20.9 & 26.7 & 214.4 \\
\hline -Large amplitude & 3.3 & 7.6 & 34.8 & 5.3 & 9.0 & 42.3 & 25.1 & 37.0 & 222.3 \\
\hline Returns & & $P$ & & & & & & & \\
\hline Stationary & 2.7 & 3.8 & 16.4 & 4.6 & 6.3 & 26.8 & 22.4 & 30.5 & 131.3 \\
\hline -Small variance & 2.7 & 3.8 & 16.3 & 4.6 & 6.3 & 26.5 & 21.9 & 30.3 & 131.3 \\
\hline -Large variance & 2.7 & 3.8 & 16.6 & 4.7 & 6.3 & 26.3 & 22.4 & 30.5 & 130.9 \\
\hline Positive trend & 3.9 & 5.1 & 34.8 & 5.3 & 6.9 & 35.5 & 22.6 & 33.2 & 129.5 \\
\hline -Small trend & 3.5 & 4.5 & 29.4 & 5.1 & 6.6 & 33.7 & 19.5 & 29.6 & 128.7 \\
\hline -Large trend & 4.3 & 5.8 & 40.2 & 5.5 & 7.0 & 36.4 & 22.6 & 33.2 & 129.5 \\
\hline Negative trend & 3.3 & 4.8 & 41.0 & 5.3 & 6.7 & 45.3 & 23.6 & 37.0 & 222.3 \\
\hline -Small trend & 3.5 & 4.8 & 34.4 & 5.5 & 6.8 & 37.6 & 23.6 & 35.5 & 219.8 \\
\hline -Large trend & 3.1 & 4.8 & 47.7 & 5.2 & 6.6 & 50.8 & 21.0 & 37.0 & 222.3 \\
\hline Seasonal & 2.7 & 3.8 & 17.9 & 4.6 & 6.3 & 29.8 & 25.1 & 30.3 & 132.5 \\
\hline -Small amplitude & 2.6 & 3.7 & 17.8 & 4.6 & 6.3 & 29.9 & 23.6 & 30.3 & 131.5 \\
\hline -Large amplitude & 2.7 & 3.8 & 18.0 & 4.7 & 6.3 & 29.7 & 25.1 & 30.3 & 132.5 \\
\hline Return ratio* & & & & & & & & & \\
\hline 0.3 & 2.1 & 3.0 & 5.0 & 3.9 & 5.7 & 6.1 & 18.8 & 30.5 & 26.1 \\
\hline 0.5 & 2.8 & 4.0 & 13.7 & 4.9 & 6.5 & 18.6 & 21.9 & 29.8 & 101.5 \\
\hline 0.7 & 3.3 & 4.4 & 30.6 & 4.9 & 6.7 & 37.8 & 22.4 & 29.1 & 131.3 \\
\hline Set-up cost $K$ & & & & & & & & & \\
\hline 200 & 1.1 & 1.5 & 8.5 & 2.8 & 3.1 & 9.4 & 23.6 & 34.0 & 67.9 \\
\hline 500 & 1.9 & 2.4 & 16.7 & 2.9 & 3.4 & 20.4 & 23.3 & 27.5 & 88.5 \\
\hline 2000 & 6.1 & 8.8 & 49.1 & 6.2 & 7.5 & 43.6 & 25.1 & 37.0 & 222.3 \\
\hline Returns hold. cost $h^{r}$ & & & & & & & & & \\
\hline 0.2 & 2.0 & 2.9 & 26.2 & 4.1 & 5.5 & 42.3 & 19.6 & 32.4 & 222.3 \\
\hline 0.5 & 3.2 & 4.6 & 24.8 & 5.2 & 7.0 & 35.1 & 23.6 & 37.0 & 189.4 \\
\hline 0.8 & 3.8 & 5.1 & 23.3 & 5.2 & 6.9 & 32.7 & 25.1 & 35.5 & 170.2 \\
\hline
\end{tabular}

* Only examples with stationary returns are considered.

Table 3: Sensitivity analysis on the performance of the SM, LUC, and PPB heuristics for the case with a joint set-up cost. 


\begin{tabular}{|c|c|c|c|c|c|c|c|c|c|}
\hline & \multicolumn{9}{|c|}{ Percentage Cost Error } \\
\hline & \multicolumn{3}{|c|}{ Average } & \multicolumn{3}{|c|}{ Standard deviation } & \multicolumn{3}{|c|}{ Maximum } \\
\hline & SM & LUC & PPB & SM & LUC & PPB & SM & LUC & PPB \\
\hline All instances & 8.3 & 9.0 & 19.8 & 8.7 & 8.7 & 19.6 & 82.5 & 98.4 & 221.4 \\
\hline Demand & & & & & & & & & \\
\hline Stationary & 8.1 & 8.7 & 21.4 & 9.0 & 8.9 & 22.4 & 76.3 & 66.0 & 221.4 \\
\hline -Small variance & 7.6 & 7.8 & 21.2 & 8.5 & 8.9 & 22.3 & 61.4 & 62.4 & 218.0 \\
\hline -Large variance & 8.6 & 9.5 & 21.7 & 9.9 & 9.0 & 22.3 & 76.3 & 66.0 & 221.4 \\
\hline Positive trend & 7.4 & 7.7 & 15.8 & 7.3 & 7.2 & 200.7 & 82.5 & 68.4 & 151.1 \\
\hline -Small trend & 7.4 & 7.8 & 16.8 & 7.5 & 7.2 & 14.3 & 82.5 & 68.4 & 145.7 \\
\hline -Large trend & 7.4 & 7.7 & 14.8 & 7.0 & 7.1 & 14.0 & 39.3 & 39.1 & 151.1 \\
\hline Negative trend & 9.5 & 9.3 & 17.2 & 8.1 & 8.0 & 12.5 & 60.3 & 64.4 & 107.5 \\
\hline -Small trend & 9.4 & 9.0 & 17.7 & 7.8 & 7.5 & 13.0 & 60.3 & 64.4 & 107.5 \\
\hline -Large trend & 9.6 & 9.6 & 16.7 & 8.5 & 8.5 & 11.9 & 54.7 & 61.6 & 90.0 \\
\hline Seasonal & 8.3 & 9.6 & 22.3 & 9.4 & 9.4 & 22.6 & 79.9 & 98.4 & 219.5 \\
\hline -Small amplitude & 7.8 & 8.5 & 21.6 & 8.9 & 9.0 & 22.3 & 79.9 & 85.0 & 219.5 \\
\hline -Large amplitude & 8.8 & 10.8 & 23.0 & 9.7 & 9.7 & 22.9 & 69.1 & 98.4 & 216.2 \\
\hline Returns & & 8 & & & & & & & \\
\hline Stationary & 7.5 & 8.2 & 16.2 & 7.4 & 7.3 & 11.7 & 53.5 & 50.6 & 88.1 \\
\hline -Small variance & 7.5 & 8.2 & 16.2 & 7.3 & 7.3 & 11.4 & 48.9 & 48.3 & 88.1 \\
\hline -Large variance & 7.4 & 8.2 & 16.3 & 7.5 & 7.2 & 11.7 & 53.5 & 50.6 & 87.5 \\
\hline Positive trend & 10.9 & 11.6 & 23.1 & 11.5 & 11.7 & 18.8 & 76.3 & 98.4 & 184.6 \\
\hline -Small trend & 10.4 & 11.1 & 21.2 & 11.3 & 11.3 & 17.6 & 76.3 & 90.4 & 91.1 \\
\hline -Large trend & 11.4 & 12.1 & 25.0 & 11.7 & 12.1 & 19.7 & 70.9 & 98.4 & 184.6 \\
\hline Negative trend & 8.9 & 9.9 & 30.7 & 9.9 & 9.6 & 32.9 & 82.5 & 68.6 & 221.4 \\
\hline -Small trend & 8.0 & 9.2 & 30.4 & 8.8 & 9.2 & 37.0 & 66.1 & 63.1 & 221.4 \\
\hline -Large trend & 9.8 & 10.5 & 31.0 & 10.9 & 10.2 & 28.2 & 82.5 & 68.6 & 172.0 \\
\hline Seasonal & 7.3 & 7.9 & 15.4 & 6.8 & 6.7 & 11.9 & 57.1 & 53.1 & 87.9 \\
\hline -Small amplitude & 7.3 & 7.8 & 15.4 & 6.7 & 6.7 & 11.6 & 56.5 & 47.3 & 85.7 \\
\hline -Large amplitude & 7.3 & 7.9 & 15.5 & 6.9 & 6.8 & 12.0 & 57.1 & 53.1 & 87.9 \\
\hline Return ratio* & & & & & & & & & \\
\hline 0.3 & 5.6 & 6.5 & 11.0 & 5.5 & 5.9 & 7.6 & 26.8 & 29.9 & 37.9 \\
\hline 0.5 & 8.0 & 8.9 & 18.0 & 8.3 & 8.3 & 11.2 & 44.0 & 42.9 & 63.5 \\
\hline 0.7 & 8.9 & 9.3 & 19.7 & 7.6 & 7.2 & 13.6 & 53.5 & 50.6 & 88.1 \\
\hline Man. set-up cost $K^{m}$ & 2 & & 17 o & 76 & 78 & 160 & 825 & 686 & 1511 \\
\hline 500 & 6.9 & 7.2 & 18.0 & $\begin{array}{l}1.0 \\
6.9\end{array}$ & 6.7 & $\begin{array}{l}10.0 \\
15.2\end{array}$ & 53.6 & 56.3 & 116.9 \\
\hline 2000 & 11.8 & 12.2 & 24.6 & 10.2 & 10.2 & 24.9 & 76.3 & 98.4 & 221.4 \\
\hline Reman. set-up cost $K^{r}$ & & & & & & & & & \\
\hline 200 & 11.3 & 11.3 & 27.1 & 9.8 & 9.7 & 22.3 & 76.3 & 98.4 & 221.4 \\
\hline 500 & 9.0 & 9.6 & 21.5 & 7.8 & 8.1 & 20.0 & 82.5 & 68.6 & 151.1 \\
\hline 2000 & 4.7 & 6.1 & 10.8 & 6.9 & 7.3 & 10.9 & 48.4 & 67.9 & 72.1 \\
\hline Returns hold. cost $h^{r}$ & & & & & & & & & \\
\hline 0.2 & 5.5 & 6.0 & 12.1 & 7.2 & 7.1 & 17.5 & 69.1 & 57.8 & 216.2 \\
\hline 0.5 & 8.3 & 9.1 & 22.1 & 8.7 & 8.5 & 18.7 & 82.5 & 75.1 & 221.4 \\
\hline 0.8 & 11.2 & 11.9 & 25.4 & 9.1 & 9.2 & 19.8 & 79.9 & 98.4 & 220.4 \\
\hline
\end{tabular}

${ }^{*}$ Only examples with stationary returns are considered.

http://mc.manuscriptcentral.com/tprs Email: ijpr@lboro.ac.uk

Table 4: Sensitivity analysis on the performance of the SM, LUC, and PPB heuristics for the case with separate set-up costs. 


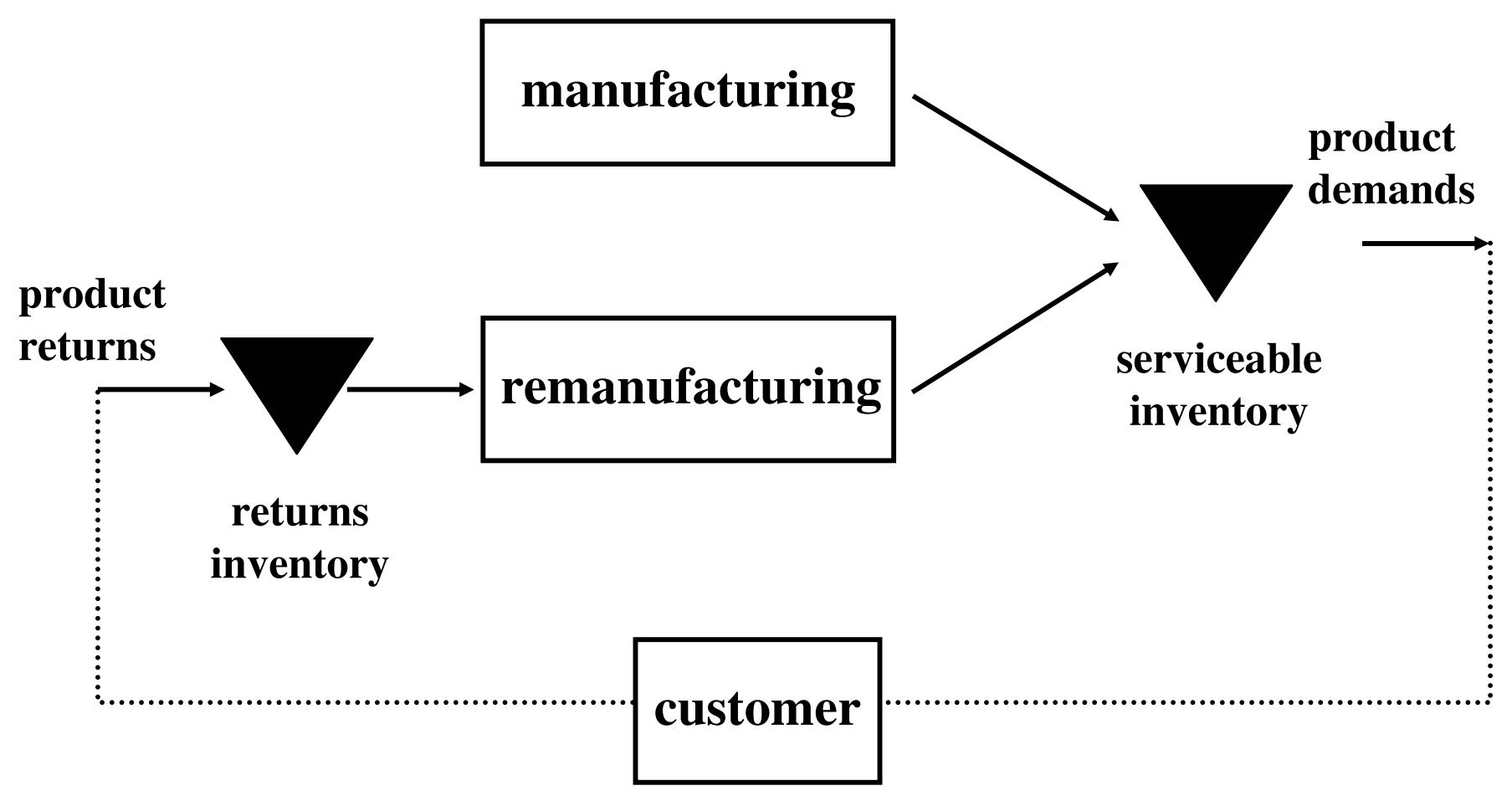

